Foreword

\title{
Precision Surgery in Obstetrics and Gynecology: Surgical Approaches for Various Uterine Fibroids
}

Yuji Hiramatsu, MD, PhD ${ }^{1}$

\footnotetext{
${ }^{1}$ Department of Obstetrics \& Gynecology, Okayama City General Medical Center, Kita-Ku, Okayama, Japan
}

Surg J 2020;6(suppl S1):S1.

It is a great pleasure to publish the second issue of Precision Surgery in Obstetrics and Gynecology (PSOG), a supplement to The Surgery Journal. The second issue of PSOG focuses on "Surgical Approaches for Various Uterine Fibroids."

We previously published a Japanese book series (24 volumes), entitled Obstetric and Gynecologic Surgery Now (OGS Now) ${ }^{1}$ with the Japanese medical publisher, Medical View, Inc. In PSOG, we are selecting representative operations from OGS Now series and demonstrating the updated operative techniques.

The operation for uterine fibroids is the most frequent and essential gynecological surgery. When performing a total hysterectomy or myomectomy, the difficulty of the operation varies greatly depending on the location, size, and number of fibroids. This time, we selected seven particularly difficult operations for uterine fibroids. All of the papers published in this volume were written by the experts in this field in Japan and are explained using easy-tounderstand illustrations and photographs that show the surgical techniques, tips, and precautions.

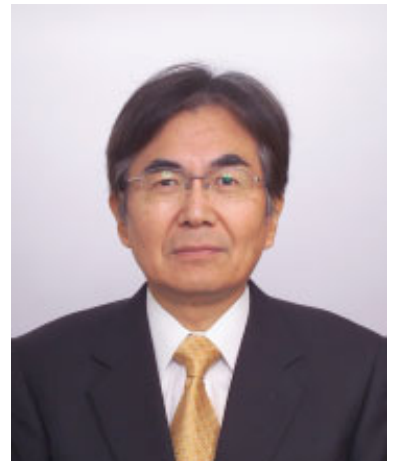

Yuji Hiramatsu MD, PhD
We hope that the procedures listed in PSOG will be helpful in performing difficult uterine fibroid operations.

Finally, I would like to express my sincere thanks to Medical View for allowing us to use the illustrations and photos used in the OGS Now series.

Conflict of Interest

None.

\section{Reference}

1 Hiramatsu Y, Konishi I, Sakuragi N, Takeda S. Obstetric and Gynecologic Surgery Now (OGS Now). Vol. 1-24. Tokyo: Medical View; 2010
Address for correspondence Yuji Hiramatsu, MD, PhD, Okayama City General Medical Center, 3-20-1 Kitanagase Omotematchi, Kita-Ku, Okayama 700-8557, Japan

(e-mail: kiki1063@cc.okayama-u.ac.jp).
DOI https://doi.org/ 10.1055/s-0040-1710532. ISSN 2378-5128.
Copyright $\odot 2020$ by Thieme Medical Publishers, Inc., 333 Seventh Avenue, New York, NY 10001, USA. Tel: +1(212) 760-0888.

\section{License terms}

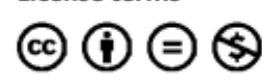

